\title{
Fractional Cointegration of Voting and Non-Voting Shares ${ }^{\#}$
}

\author{
Ingolf Dittmann $\$$
}

October 1998

\begin{abstract}
:
Voting and non-voting shares of ten German companies are analyzed for fractional cointegration. It turns out that seven pairs of price series are fractionally cointegrated, which means that for each pair there is a linear combination of the two series that is a long-memory process.

If two stocks are fractionally cointegrated, future returns of at least one of the stocks can be predicted by past prices. This contradicts the weak form of the efficient market hypothesis. A simple trading strategy is proposed and analyzed; it leads to considerable excess returns in two out-of-sample evaluations.
\end{abstract}

Keywords: efficient market hypothesis; fractional cointegration; non-voting shares; preferred stocks; voting premium

\# I like to thank Walter Krämer for helpful discussions and comments. I also thank Christian Kleiber, Wolfgang Leininger, Wolfram Richter, Andreas Römer and Jürgen Schweiger. Financial support by Deutsche Forschungsgemeinschaft, Graduiertenkolleg "Allokationstheorie, Wirtschaftspolitik und kollektive Entscheidungen" and Sonderforschungsbereich 475 "Komplexitätsreduktion in multivariaten Datenstrukturen" is gratefully acknowledged. The data of the paper's empirical part were supplied by Deutsche Finanzdatenbank Karlsruhe.

$\S$ University of Dortmund, Department of Economics, Graduiertenkolleg, D-44221 Dortmund, Germany. E-mail: fw-indi@wiso.wiso.uni-dortmund.de 


\section{Introduction}

The weak form of the efficient market hypothesis (henceforth EMH) claims that asset prices fully reflect the information contained in the historical sequence of prices, so that there are no investment strategies which yield abnormal profits on the basis of past prices. Malkiel (1989) and Fama $(1970,1991)$ review the vast literature on tests of the EMH. They both conclude that all in all there is strong evidence in favour of the weak form of the efficient market hypothesis. The only serious threat to the EMH are some seasonal patterns, like the January effect or the weekend effect, which are quite small, so that they cannot be exploited if transaction costs must be paid.

By far the largest part of this literature concentrates on the analysis of univariate price series, i.e. on whether future returns of a given asset can be forecasted by past prices of the same asset. In the past twenty years, powerful multivariate time series methods have been developed that allow to study whether future returns of one asset can be predicted by past prices of a set of assets. One prominent multivariate concept is that of cointegration.

Consider two stock price series that can be described by a random walk individually. The two stocks are called cointegrated if there exists a linear combination of the two series that is not a random walk, but stationary. If two stocks are cointegrated, Granger's representation theorem states that future returns of at least one of the two shares can be predicted by past prices of both series (see e.g. Granger, 1987). Consequently, asset prices from an informationally efficient market cannot be cointegrated ${ }^{1}$ and tests for cointegration can be used to test the efficient market hypothesis.

Cointegration studies have been presented by Taylor \& Tonks (1989) and Kasa (1992) for international stock market data, by Cerchi \& Havenner (1988) for American and by Krämer (1997) for German stock market data. They all find evidence for cointegration in their data. However, as there are thousands of assets available, this evidence - especially when national stock markets are considered - may well be due to data-mining or to the publication bias. The problem of data mining can be tackled by considering only sets of stocks that share a common property, e.g. stocks that are issued by the same company. This is the reason why this paper concentrates on cointegration of voting and non-voting shares of the same company.

1 To be more precise, the EMH can only hold if the two stocks are either not cointegrated, i.e. any linear combination of the two series is a random walk itself, or if they are "perfectly" cointegrated, which means that there is a linear combination of the two stocks that is a constant. 
Motivated by Krämer's (1997) findings of evidence that the equilibrium error process of two cointegrated stock price series is a long-memory process, the more general framework of fractional cointegration is employed in this paper. Two random walks are called fractionally cointegrated, if there exists a linear combination of the two series that is not a random walk but a long memory-process. A long-memory process can be - but need not be - stationary. It allows for wide and long-lasting deviations from equilibrium. In the applied literature, fractional cointegration has already been used to model purchasing power parity (Cheung \& Lai, 1993), exchange rates (Baillie \& Bollerslev, 1994) and interest rate futures (Booth \& Tse, 1995).

The paper is organized as follows: Section 2 presents the main properties of German voting and non-voting shares and briefly reviews the empirical literature on the price difference between the two kinds of shares. In Section 3, the concept of fractional cointegration is introduced, properties of fractionally cointegrated time series are discussed and a test of the hypothesis "no cointegration" is presented. The data set is introduced in Section 4, followed by the empirical analysis. It turns out that seven out of ten considered pairs of voting and non-voting shares are fractionally cointegrated. In Section 5, a simple trading strategy is introduced and analyzed; it leads to considerable excess returns in two out-of-sample evaluations. Finally, the paper's main results are summarized and discussed in Section 6.

\section{Non-Voting Shares, Preferred Dividends and the Voting Premium}

German law requires that any share without a voting right must be vested with a cumulative preferred dividend. This is a fixed nominal amount that must be paid annually for each non-voting share before holders of the corresponding voting shares receive any dividend. If the preferred dividend cannot be settled completely, next year's claim increases by the unsettled amount. Further, if the preferred dividend is not paid in two consecutive years, each non-voting share receives a voting right until the arrears are paid fully.

Therefore, the total dividend is distributed among the two kinds of shares in the following order: First, preferred dividends and arrears are settled. Then, for each voting share an amount equal to the preferred dividend is payed. What remains is distributed equally among all shares. Consequently, the dividend of a voting share never exceeds 
that of a non-voting share. For some companies, the non-voting share's dividend always exceeds the voting share's by an additional dividend yield. In case of liquidation, both types of stocks are treated equally.

As most companies never issue more than one kind of non-voting shares, trades occur frequently for voting and non-voting shares, so that complete time series data are available for long periods.

Although a voting share's dividend never exceeds the corresponding non-voting share's dividend, voting shares are usually traded at a higher price than non-voting shares. $^{2}$ This difference is called "voting premium". It is usually explained by indirect benefits that can only be derived by the holders of voting shares or the majority of them.

There are several empirical studies of the voting premium: Lease, McConnell \& Mikkelson (1983) estimate the average relative voting premium for various US companies whose different kinds of outstanding stocks solely differ in the number of votes per share. Rydqvist (1996) does the same for Swedish stock market data and regresses the relative voting premium on a variable that measures the competitiveness of the company's ownership structure. A similar analysis is performed for the Italian stock market by Zingales (1994), who includes the additional dividend yield of non-voting shares as an independent variable in the regression. Kunz \& Angel (1996) incorporate a few more variables in the regression that measure transferability or liquidity of the considered shares. They examine data from the Swiss stock market.

In all of these studies, the relative voting premium is assumed to be stationary around a constant which is influenced by the company's or the stock's characteristics. This means that the difference of the log prices between voting and non-voting shares is stationary. If we assume that each individual log price series is a random walk as standard theory and empirics suggest (see e.g. Fama, 1970), this implies that voting and non-voting share prices are cointegrated. Consequently, the assumptions underlying the mentioned studies imply that the considered capital markets are inefficient.

As most of these studies' results are robust, they might serve to indicate that voting and non-voting shares are indeed cointegrated. However, this hypothesis has not been tested rigorously before.

2 This observation would not be surprising if the two stocks corresponded to two (similar) companies. Then, consistently higher dividends of stock 1 could (or even should) go along with a higher price of stock 2. The point is that voting and non-voting stocks are shares of the same company. Preferred dividends are paid from the company's resources that also belong to the holders of voting shares. 


\section{Fractional Cointegration: Modelling and Testing}

Let $\mathrm{V}_{\mathrm{t}}$ and $\mathrm{N}_{\mathrm{t}}$ denote the prices of voting and non-voting shares at time $\mathrm{t}$, respectively. We assume that $\log$ prices $\mathrm{v}_{\mathrm{t}}=\ln \left(\mathrm{V}_{\mathrm{t}}\right)$ and $\mathrm{n}_{\mathrm{t}}=\ln \left(\mathrm{N}_{\mathrm{t}}\right)$ follow a random walk with uncorrelated increments:

$$
\mathrm{v}_{\mathrm{t}}=\mathrm{r}^{\mathrm{v}}+\mathrm{v}_{\mathrm{t}-1}+\varepsilon_{\mathrm{t}}^{\mathrm{v}} \text { and } \quad \mathrm{n}_{\mathrm{t}}=\mathrm{r}^{\mathrm{n}}+\mathrm{n}_{\mathrm{t}-1}+\varepsilon_{\mathrm{t}}^{\mathrm{n}},
$$

$\varepsilon_{\mathrm{t}}^{\mathrm{v}}$ and $\varepsilon_{\mathrm{t}}^{\mathrm{n}}$ are uncorrelated zero-mean error processes. Campbell, Lo \& MacKinlay (1997) discuss this model and its empirical relevance extensively. (1) implies that the individual series of continuously compounded returns $v_{t}-v_{t-1}$ and $n_{t}-n_{t-1}$, respectively, are uncorrelated and hence not predictable by past values. Consequently, (1) is consistent with the efficient market hypothesis.

$\mathrm{v}_{\mathrm{t}}$ and $\mathrm{n}_{\mathrm{t}}$ are called fractionally cointegrated, if there are constants $\alpha, \beta$ and $\gamma \in \mathrm{IR}$, such that

$$
\mathrm{n}_{\mathrm{t}}=\alpha+\beta \cdot \mathrm{v}_{\mathrm{t}}+\gamma \cdot \mathrm{t}+\mathrm{u}_{\mathrm{t}}
$$

and $\mathrm{u}_{\mathrm{t}}$ is a long memory or $\mathrm{I}(\mathrm{d})$ process with long memory parameter $\mathrm{d} \in(0,1)$. Technically, this means that the spectral density of $u_{t}$ is unbounded at frequency zero and behaves like $\lambda^{-2 d}$ as $\lambda \rightarrow 0 . u_{t}$ is stationary if $d<0.5$. For a thorough discussion of long memory processes see Baillie (1996) or Granger \& Joyeux (1980).

If the long memory parameter $d$ is zero, the equilibrium error process $u_{t}$ is a short memory process, like for instance an ARMA-process. In this case, $\mathrm{n}_{\mathrm{t}}$ and $\mathrm{v}_{\mathrm{t}}$ are classically cointegrated. On the other hand, if $d=1, u_{t}$ is integrated so that $n_{t}$ and $v_{t}$ are not cointegrated. Therefore, the concept of fractional cointegration bridges the gap between "no cointegration" and "classical cointegration", which become special cases of (2).

Equation (2) also captures the previous section's idea of a stationary voting premium, if $\beta=1, \gamma=0$ and $u_{t}$ is stationary. The term $\gamma \cdot t$ in (2) has been included, because the individual series have both a stochastic and a deterministic trend:

$$
\mathrm{v}_{\mathrm{t}}=\underset{\text { deterministic trend }}{\ldots . . . \ldots . . .}+\frac{\mathrm{v}_{0}+\varepsilon_{1}^{\mathrm{v}}+\varepsilon_{2}^{\mathrm{v}}+\ldots+\varepsilon_{\mathrm{t}}^{\mathrm{v}} .}{\text { stochastic trend }}
$$

The parameter $\gamma$ allows for the possibility that the cointegrating linear combination of the two stochastic trends differs from that of the two deterministic trends. Moreover, there is a technical reason for the inclusion of $\gamma \cdot t$ in (2): It increases the power of the Phillips-Perron test, which we introduce below. 


\section{Properties of fractionally cointegrated systems}

Granger (1986) deduces the error correction model of a fractionally cointegrated system. It implies that future returns of at least one of the two series can be predicted by today's equilibrium error $u_{t}$ and past returns of the two series. Hence, the efficient market hypothesis requires that voting and non-voting share prices must not be fractionally cointegrated.

Cheung \& Lai (1993) show that an $\mathrm{I}(\mathrm{d})$-process with $\mathrm{d}<1$ is mean-reverting, i.e. any shock to the system eventually dies out. This means that equation (2) indeed specifies an equilibrium, if $\mathrm{u}_{\mathrm{t}}$ is $\mathrm{I}(\mathrm{d})$ with $\mathrm{d}<1$. The deviations $\mathrm{u}_{\mathrm{t}}$ may be large and may persist over a long time, but eventually the system will move back to the equilibrium. If for instance the current error $u_{t}$ is positive, $n_{t}$ must decrease relative to $v_{t}$ in order to restore equilibrium sometime. And so the voting share's return is likely to be larger than the non-voting share's over the medium term. This is the intuition behind Granger's error correction model.

\section{Testing for fractional cointegration}

Since we want to test the efficient market hypothesis, the null hypothesis is that $\mathrm{v}_{\mathrm{t}}$ and $\mathrm{n}_{\mathrm{t}}$ are not cointegrated, which means that $\mathrm{u}_{\mathrm{t}}$ in (2) is $\mathrm{I}(1)$ for any $\alpha, \beta$ or $\gamma$

Tests of the hypothesis of no cointegration that are powerful against fractionally cointegrated alternatives can be constructed in two different ways: One possibility is to specify and estimate a fully parametric model, followed by an appropriate test for fractional cointegration, as in Dueker \& Startz (1997). The other way is to estimate the potential cointegrating relationship by an OLS regression and to test the residuals for a unit root with a semiparametric test, as in Cheung \& Lai (1993) or Booth \& Tse (1995). The advantage of these semiparametric residual-based tests is that one needs to estimate only those parameters that determine the long-run behaviour of the system. Since stock market prices generally exhibit complex short-run characteristics - which would lead to a complicated parametric model - we employ a residual-based test in this paper.

Depending on the unit root test that is applied to the OLS residuals, there are several possible residual-based tests of the hypothesis of no cointegration. Dittmann (1998) compares seven of these tests in an extensive Monte-Carlo study, which shows that the Phillips-Perron t-test is more powerful against fractional alternatives than the Augmented Dickey-Fuller test, the Modified Rescaled Range test and four variations of the GewekePorter-Hudak test - including the tests used in Cheung \& Lai (1993) and Booth \& Tse 
(1995). For this reason, we apply the Phillips-Perron test in this paper.

In a first step, we estimate the following regression by OLS:

$$
\mathrm{n}_{\mathrm{t}}=\hat{\boldsymbol{\alpha}}+\hat{\boldsymbol{\beta}} \mathrm{v}_{\mathrm{t}}+\hat{\boldsymbol{\gamma}} \mathrm{t}+\hat{\mathrm{u}}_{\mathrm{t}}
$$

In the second step, we apply the Phillips-Perron unit root test to the regression residuals $\hat{\mathrm{u}}_{\mathrm{t}}$ (see Hamilton (1994) for further details). This is a modified version of the OLS t-test of the null hypothesis " $\rho=1$ " in the regression

$$
\hat{\mathrm{u}}_{\mathrm{t}}=\rho \hat{\mathrm{u}}_{\mathrm{t}-1}+\mathrm{e}_{\mathrm{t}} .
$$

The test statisic is:

$$
\mathrm{Z}_{\mathrm{t}}=\sqrt{\frac{\hat{\mathrm{c}}}{\hat{\sigma}_{\mathrm{ps}}^{2}(\mathrm{q})}} \frac{\hat{\rho}-1}{\hat{\sigma}(\hat{\rho})}-\frac{1}{2}\left(\hat{\sigma}_{\mathrm{ps}}{ }^{2}(\mathrm{q})-\hat{\mathrm{c}}\right) \frac{1}{\hat{\sigma}_{\mathrm{ps}}(\mathrm{q})}\left[\frac{(\mathrm{T}-1) \hat{\sigma}(\hat{\rho})}{\mathrm{s}}\right]
$$

where $\hat{\mathrm{c}}=\frac{1}{\mathrm{~T}-1} \sum_{\mathrm{t}=2}^{\mathrm{T}} \hat{\mathrm{e}}_{\mathrm{t}}^{2}, \quad \hat{\sigma}(\hat{\rho})=\mathrm{s}^{2} \div \sum_{\mathrm{t}=2}^{\mathrm{T}} \hat{\mathrm{u}}_{\mathrm{t}-1}, \quad \mathrm{~s}^{2}=\frac{1}{\mathrm{~T}-2} \sum_{\mathrm{t}=2}^{\mathrm{T}} \hat{\mathrm{e}}_{\mathrm{t}}^{2}$ and $\hat{\sigma}_{\mathrm{ps}}{ }^{2}(\mathrm{q})$ is a consistent estimator of the long-run variance:

$$
\hat{\sigma}_{p s}^{2}(q)=\frac{1}{T} \sum_{j=1}^{T}\left(\hat{e}_{j}-\overline{\hat{e}}_{T}\right)^{2}+\frac{2}{T} \sum_{j=1}^{q-1}\left(1-\frac{j}{q}\right) \sum_{i=j+1}^{T}\left(\hat{e}_{i}-\overline{\hat{e}}_{T}\right)\left(\hat{e}_{i-j}-\overline{\hat{e}}_{T}\right) .
$$

As proposed by Cheung \& Lai (1997), the lag truncation parameter q is chosen by Andrews' (1991) data-dependent formula, i.e. $q$ is the greatest integer less than or equal to $\mathrm{k}_{\mathrm{T}}$ with

$$
\mathrm{k}_{\mathrm{T}}=\left(\frac{3 \mathrm{~T}}{2}\right)^{\frac{1}{3}}\left(\frac{2 \hat{\mathrm{r}}}{1-\hat{\mathrm{r}}^{2}}\right)^{\frac{2}{3}} \text {. }
$$

$\hat{\mathrm{r}}$ is the estimated first-order autocorrelation of $\hat{\mathrm{e}}_{\mathrm{i}}$.

Dittmann (1998) discovers that the power of this Phillips-Perron test increases in large samples if $\hat{\gamma} \mathrm{t}$ is included in the cointegration regression (4) even if $\gamma$ is known to be zero in (2). We use the critical values provided by Dittmann (1998), which do not differ significantly from those given by Phillips \& Ouliaris (1990). 


\section{Empirical Results for German Voting and Non-Voting Share Prices}

\section{The data set}

The available raw data consist of daily observations from 1974 to 1996 of all pairs of voting and non-voting shares traded at the stock exchange in Frankfurt. Since missing values due to holidays, weekends or no trading can distort the periodogram seriously (see Dittmann, 1997), weekly observations are constructed by the following procedure: First the series are adjusted for dividends, stock splits, etc. and all observations with no or only low trading are discarded. Then for each individual series, weekly observations are generated by selecting Wednesday's observation. If this observation is missing, Tuesday's (then Thursday's, Monday's, Friday's) observation is used instead. The advantage of mid-week observations is that only few German holidays fall on

\begin{tabular}{|c|c|c|c|c|}
\hline $\begin{array}{l}\text { company, } \\
\text { main field of } \\
\text { activity }^{3}\end{array}$ & $\begin{array}{c}\text { number of } \\
\text { observations, } \\
\text { time period }\end{array}$ & $\begin{array}{l}\text { preferred } \\
\text { dividend }^{3} \\
\text { (DM) }\end{array}$ & $\begin{array}{l}\text { extra } \\
\text { dividend }^{3} \\
\text { (DM) }\end{array}$ & $\begin{array}{c}\text { large } \\
\text { voting stock } \\
\text { holders }^{3}\end{array}$ \\
\hline $\begin{array}{l}\text { Asko } \\
\text { retail trade }\end{array}$ & $\begin{array}{c}602 \\
43 / 84-18 / 96\end{array}$ & 2.50 & $0.00-2.50$ & $\begin{array}{l}55 \% \text { Metro } \\
11 \% \text { WestLB } \\
11 \% \text { BEGOHA }\end{array}$ \\
\hline $\begin{array}{l}\text { Babcock } \\
\text { engineering }\end{array}$ & $\begin{array}{c}1058 \\
45 / 74-6 / 95\end{array}$ & 3.00 & 0.50 & $10 \%$ WestLB \\
\hline $\begin{array}{l}\text { Dyckerhoff } \\
\text { building materials }\end{array}$ & $\begin{array}{c}496 \\
26 / 82-51 / 91\end{array}$ & 2.50 & - & $\begin{array}{l}42 \% \text { family property } \\
15 \% \text { Dresdner Bank }\end{array}$ \\
\hline $\begin{array}{l}\text { Herlitz } \\
\text { writing materials }\end{array}$ & $\begin{array}{c}436 \\
52 / 87-18 / 96 \\
\end{array}$ & 1.92 & 0.64 & $60 \%$ family property \\
\hline $\begin{array}{l}\text { KSB } \\
\text { pumps, fittings }\end{array}$ & $\begin{array}{c}756 \\
9 / 81-33 / 95\end{array}$ & 2.00 & $0.50-1.00$ & $\begin{array}{l}\text { 74\% Klein Pumpen } \\
\text { GmbH }\end{array}$ \\
\hline $\begin{array}{l}\text { Lufthansa } \\
\text { air traffic }\end{array}$ & $\begin{array}{c}1166 \\
1 / 74-18 / 96\end{array}$ & 2.50 & - & $\begin{array}{l}36 \% \mathrm{BRD} \\
10 \% \mathrm{MGL}\end{array}$ \\
\hline $\begin{array}{l}\text { MAN } \\
\text { commercial vehicles }\end{array}$ & $\begin{array}{c}1099 \\
16 / 75-18 / 96\end{array}$ & 2.00 & - & $>25 \%$ Regina \\
\hline $\begin{array}{l}\text { Rheinmetall } \\
\text { holding, engineering }\end{array}$ & $\begin{array}{c}601 \\
44 / 84-18 / 96\end{array}$ & 3.00 & 1.00 & 67\% Röchling \\
\hline $\begin{array}{l}\text { RWE } \\
\text { utilities }\end{array}$ & $\begin{array}{c}1166 \\
1 / 74-18 / 96 \\
\end{array}$ & 2.50 & - & $>50 \%$ communities \\
\hline $\begin{array}{l}\text { WMF } \\
\text { kitchen utensils }\end{array}$ & $\begin{array}{c}426 \\
44 / 81-51 / 89\end{array}$ & 3.00 & - & $\begin{array}{l}\text { 28\% Helvetic } \\
\text { 17\% Deutsche Bank } \\
\text { 17\% Münchner Rück } \\
\text { 17\% Württembg. AG }\end{array}$ \\
\hline
\end{tabular}

Table 1: Description of the companies and their stocks under consideration

3 Source: "Handbuch der deutschen Aktiengesellschaften", 1995/96, Verlag Hoppenstedt, Darmstadt. 
Wednesdays or Tuesdays and that the well-known anomalies at the end or beginning of the week are circumvented. After merging voting and non-voting stock series, those ten companies are selected that show the longest period of time without missing values in either series.

Table 1 shows the ten accordingly selected companies, as well as the number and period of observations used in the empirical analysis. The third column of Table 1 displays the cumulative preferred dividend, which is the minimum dividend that has to be paid annually for each non-voting share. The fourth column shows the additional dividend yield by which the non-voting share's dividend must exceed the voting share's dividend. For 'Asko' and 'KSB', the additional dividend depends upon the dividend paid for voting shares. Here, the range of the additional dividend is given.

Figure 1 shows voting and non-voting share prices of 'Lufthansa'. The two series stay close together and clearly look cointegrated.

\section{Testing the individual series for a unit root}

Before testing whether there is a non-integrated linear combination of voting and nonvoting share prices, we have to make sure that the individual series are indeed integrated, i.e. that equation (1) holds. For this reason, each of the twenty individual series is tested for being a random walk against the alternative of being trend stationary. We conduct the Phillips-Perron test and the Phillips-Perron t-test as described in Hamilton (1994) with the lag truncation parameters 5, 10 and 20.

For both series of 'Babcock' as well as 'Rheinmetall' non-voting shares, the random walk hypothesis is rejected at the $5 \%$ level by all tests. For 'Rheinmetall' voting shares, four of the six tests reject. Since any linear combination of two trend stationary time series is trend stationary as well, the concept of cointegration is not applicable for the stocks of these two companies. Therefore, we exclude them from further analysis. Note



Figure 1: Log-prices of 'Lufthansa' voting and non-voting shares 
that trend stationarity contradicts the efficient market hypothesis, too, since future changes of a trend stationary time series can be predicted from past values of the series.

For 'Asko' voting shares as well as 'RWE' non-voting shares, the random walk hypothesis is also rejected at the $5 \%$ level by most tests. For the associated series however, all tests remain insignificant. Since cointegrating relation (2) can only hold if both series are integrated or both series are (trend) stationary, we do not discard 'Asko' or 'RWE'. Nevertheless, one must be cautious when interpreting the following results for these two companies. In the remaining twelve series, the unit root tests do not find any evidence against the random walk hypothesis (not even at the $10 \%$ significance level).

\section{Evidence for cointegration}

Table 2 displays the OLS estimates for cointegration regression (4), the PhillipsPerron t-test statistic $Z_{t}$ as given in (6) and the corresponding p-values. Except for 'RWE', the Phillips-Perron t-test rejects the hypothesis of no cointegration clearly. Thus, seven of our initial ten pairs of price series are indeed cointegrated.

\begin{tabular}{lcccccc}
\hline \multirow{2}{*}{ company } & \multicolumn{2}{c}{ cointegration regression estimates } & & \multicolumn{2}{c}{ Phillips-Perron t-test } \\
\cline { 2 - 3 } \cline { 6 - 7 } \cline { 6 - 7 } & $\hat{\boldsymbol{\alpha}}$ & $\hat{\boldsymbol{\beta}}$ & $\hat{\boldsymbol{\gamma}}$ & & $\mathrm{Z}_{\mathrm{t}}$ & $\mathrm{p}$-value \\
\hline Asko & -1.13 & 1.11 & 0.00046 & & -5.976 & $1 \%$ \\
Dyckerhoff & -0.21 & 1.01 & -0.00027 & & -5.010 & $1 \%$ \\
Herlitz & 0.36 & 0.84 & 0.00113 & & -4.096 & $2.5 \%$ \\
KSB & 0.47 & 0.87 & 0.00019 & & -9.197 & $1 \%$ \\
Lufthansa & -0.09 & 0.98 & 0.00005 & & -4.470 & $1 \%$ \\
MAN & 0.42 & 0.88 & 0.00005 & & -8.319 & $1 \%$ \\
RWE & 0.26 & 0.80 & 0.00024 & & -3.762 & $7.5 \%$ \\
WMF & -0.33 & 1.05 & -0.00056 & & -4.529 & $1 \%$ \\
\hline
\end{tabular}

Table 2: Estimates of the cointegrating equation and evidence for cointegration for eight pairs of voting and non-voting shares.

\section{Interpretation of the cointegration regression estimates}

The idea of a "voting premium" seems to be appropriate for 'Dyckerhoff', 'Lufthansa' and 'WMF'. For these three companies, $\hat{\beta}$ is close to 1 , so that the relative voting premium becomes

$$
\frac{\mathrm{V}_{\mathrm{t}}-\mathrm{N}_{\mathrm{t}}}{\mathrm{V}_{\mathrm{t}}}=1-\mathrm{e}^{\alpha+\gamma \mathrm{t}}
$$

As $\hat{\alpha}$ and $\hat{\gamma}$ are negative for these three companies, relative voting premiums are positive. The premium of 'Lufthansa' is roughly constant over time, whereas the 
premiums of 'Dyckerhoff' and 'WMF' increase over time.

A more general interpretation of the estimates in Table 2 can be obtained by considering equation (3) again. It states that the voting share's $\log$ price $\mathrm{v}_{\mathrm{t}}$ is the sum of a stochastic trend, which is the source of risk, and a deterministic trend, which guarantees an average positive return. Substituted into (2) we get:

$$
\mathrm{n}_{\mathrm{t}}=\alpha+\left(\beta \cdot \mathrm{r}^{\mathrm{v}}+\gamma\right) \cdot \mathrm{t}+\beta \cdot\left(\mathrm{v}_{0}+\varepsilon_{1}^{\mathrm{v}}+\varepsilon_{2}^{\mathrm{v}}+\ldots+\varepsilon_{\mathrm{t}}^{\mathrm{v}}\right)+\mathrm{u}_{\mathrm{t}}
$$

If $\beta$ is smaller than one, non-voting shares bear less risk than voting shares, because $\mathrm{v}_{0}+\varepsilon_{1}^{\mathrm{v}}+\varepsilon_{2}^{\mathrm{v}}+\ldots+\varepsilon_{\mathrm{t}}^{\mathrm{v}}$ is the only source of risk for both series. This is the case for 'Herlitz', 'KSB' and 'MAN'; for these companies $\hat{\beta}$ is around 0.86 and $\hat{\alpha}$ and $\hat{\gamma}$ are positive. Here, $\gamma$ being positive can be interpreted as a partial compensation for the simultaneous reduction of average return, as $\beta \cdot \mathrm{r}^{\mathrm{v}}<\mathrm{r}^{\mathrm{v}}$. Size and sign of $\alpha$ are irrelevant if risk and average returns are considered. Adding the constant $\alpha$ in (2) corresponds to an adjustment of the non-voting share's face value.

For 'Dyckerhoff', 'Lufthansa' and 'WMF', non-voting shares bear approximately the same risk as voting shares, because $\hat{\beta} \approx 1$. A peculiar case is 'Asko', whose non-voting shares bear more risk than voting shares $(\hat{\mathcal{B}}=1.11)$. This is rewarded by an extra average return $(\gamma>0)$.

\section{The cointegration regression residuals}

The results in Table 2 indicate that seven pairs of voting and non-voting shares are cointegrated. Now we are going to examine the regression residuals in order to show that these pairs are fractionally cointegrated. Figure 2 displays the residuals of regression (4) for 'Lufthansa'. This series rarely crosses the horizontal axis but exhibits

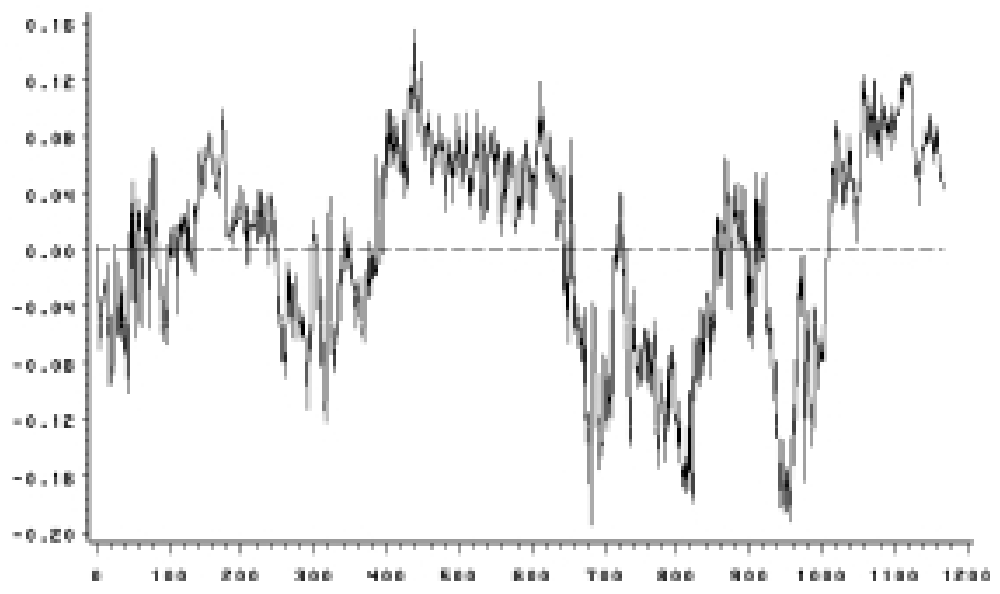

Figure 2: Cointegration regression residuals for 'Lufthansa' 

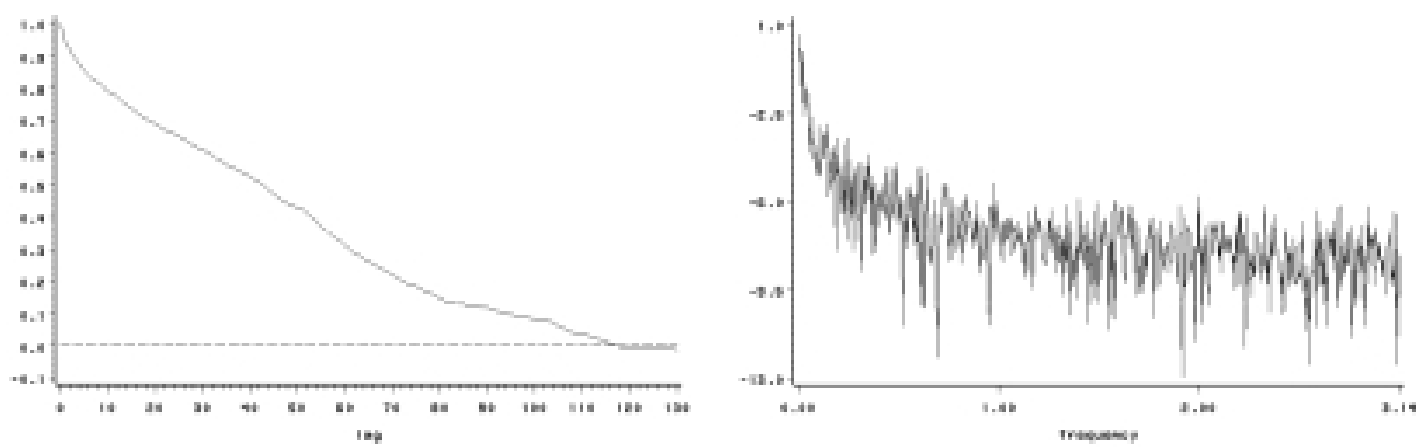

Figures 3 and 4: Autocorrelations and log-periodogram of 'Lufthansa' cointegration regression residuals

wide, long-lasting deviations from its mean. The empirical autocorrelations, shown inFigure 3, decrease very slowly with increasing lags and the corresponding periodogram in Figure 4 clearly has a pole at the origin. These figures therefore suggest that the regression residuals of 'Lufthansa' have long memory.

Table 3 displays three Geweke \& Porter-Hudak (1983) estimates of the long memory parameter $\mathrm{d}^{*}$ of regression residuals $\hat{\mathrm{u}}_{t}$ for each of the seven pairs of stocks. The estimates are calculated from a periodogram regression which runs across the first $\mathrm{T}^{\mathrm{n}}$ smallest Fourier frequencies, where $\mathrm{T}$ is the number of observations and $\mathrm{n}$ is $0.5,0.55$ and 0.6, respectively. Except for 'Asko' and 'KSB', all estimates are larger than 0.5, which implies that the estimated residual's process $\hat{\mathrm{u}}_{\mathrm{t}}$ is not stationary. Cheung \& Lai (1993) and Dittmann (1998) present some evidence that the long memory parameter $\mathrm{d}^{*}$ of regression residuals $\hat{u}_{t}$ is smaller than the long memory parameter $d$ of the true but unobservable residuals $u_{t}$, because the OLS regression usually reduces too much variance and thereby produces a 'bias towards stationarity'. So it might well be, that even 'Asko' and 'KSB' have an instationary cointegration residual process $u_{t}$.

\begin{tabular}{lccc}
\hline & \multicolumn{3}{c}{ GPH estimate of long memory parameter } \\
\cline { 2 - 4 } \multicolumn{1}{c}{ company } & $\mathbf{n = 0 . 5}$ & $\mathbf{n = 0 . 5 5}$ & $\mathbf{n}=\mathbf{0 . 6}$ \\
\hline Asko & 0.47 & 0.45 & 0.59 \\
Dyckerhoff & 0.75 & 0.75 & 0.83 \\
Herlitz & 0.84 & 0.77 & 0.80 \\
KSB & 0.52 & 0.44 & 0.41 \\
Lufthansa & 0.77 & 0.84 & 0.85 \\
MAN & 0.61 & 0.55 & 0.57 \\
WMF & 0.68 & 0.62 & 0.67 \\
\hline
\end{tabular}

Table 3: Estimates of the long memory parameter of the cointegration regression residuals for seven pairs of voting and non-voting shares 


\section{Trading Strategies and Excess Return}

The previous section presented substantial evidence that seven out of ten pairs of voting and non-voting stock price series are fractionally cointegrated. As cointegration of asset prices constitutes a violation of the hypothesis of informationally efficient markets, the question arises whether this anomaly is merely statistically significant or also practically relevant. To this end, a trading strategy is proposed and evaluated in this section.

Figure 5 shows the cointegration regression residuals $\hat{u}_{t}$ for 'Lufthansa' together with two horizontal lines at -0.05 and 0.05 . Consider the following trading strategy:

1. Sell all voting shares and buy non-voting shares if $\hat{u}_{t}$ crosses the -0.05 line.

2. Sell all non-voting shares and buy voting shares if $\hat{u}_{t}$ crosses the +0.05 line.

If the cointegrating relation and this trading strategy had been known in advance, there would have been seven portfolio changes during the observation period of 1166 weeks ( $\approx 22.5$ years). Each one of these changes yields an extra return of circa $10 \%$, which has to be added to the equilibrium return that realized in between. ${ }^{4}$ The corresponding waiting times would have been between 60 and 260 weeks with an average of less than three years. Certainly, this trading strategy would have been worthwhile even in the presence of high trading costs.

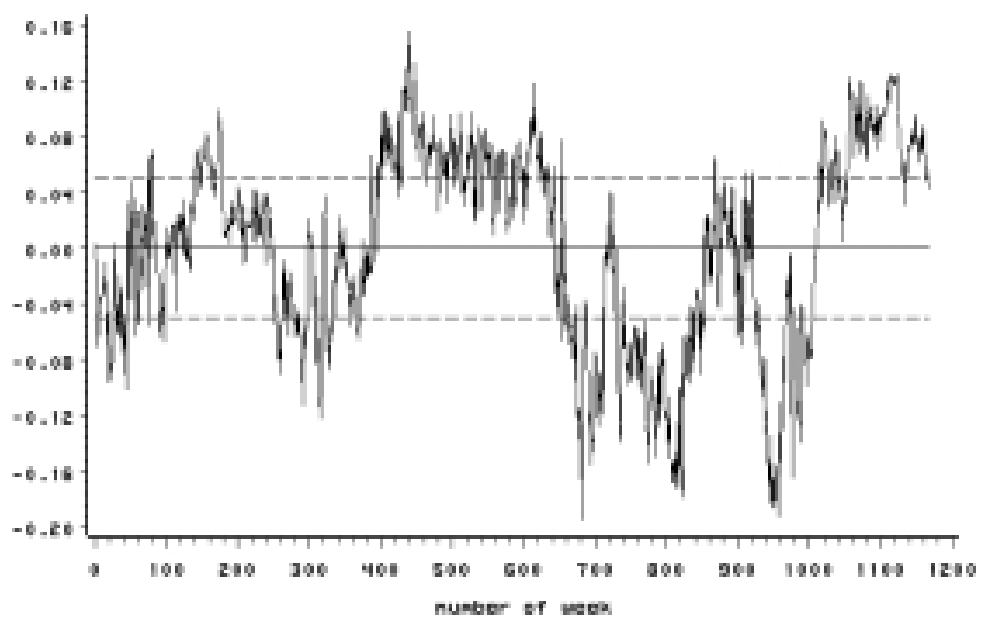

Figure 5: Cointegration regression residuals for 'Lufthansa' with boundaries of the $10 \%$ trading strategy

4 Since we consider $\log$ prices, $\mathrm{u}_{\mathrm{t}}=0.05$ means that non-voting shares are overpriced by $\exp \left(\mathrm{u}_{\mathrm{t}}\right)-1 \approx 5 \%$ at time $\mathrm{t}$ relative to the long-run equilibrium. 
Of course, this is only an ex-post evaluation, which consequently is biased toward success. Unfortunately, an ex-ante evaluation is not possible anymore for most of the considered pairs of voting and non-voting shares, because the available series have not been divided into two parts in advance. Instead, the whole sample has been used for testing, because fractional cointegration is a long-run phenomenon that therefore needs long time series to be detected. Merely for 'WMF' and 'Dyckerhoff', an ex-ante evaluation is still possible, as the corresponding series are divided into two parts due to missing values. ${ }^{5}$ The second period of the available sample, which consists of 333 weeks for 'WMF' and 227 weeks for 'Dyckerhoff', has not been used for the calculation of the estimates and test statistics shown in Table 2.

Table 4 displays the total returns for four trading strategies over this second period. Here, the strategy presented above is called the $10 \%$ strategy, because the distance between the two trading thresholds is 0.1 . The $5 \%$ strategy refers to the corresponding rule with threshold levels -0.025 and +0.025 . Further, the two bench mark strategies 'holding voting shares only' and 'holding non-voting shares only' are considered, too.

Table 4 shows that constant holding of 'WMF' non-voting shares from week 1/1990 until week 18/1996 results in a loss of $30.4 \%$ of the invested money, whereas the $5 \%$ trading strategy leads to a gain of $31 \%$, if there are no transaction costs. In the presence of $1 \%$ transaction costs, that have to be paid for each of the 15 portfolio changes, the $5 \%$ strategy ends up with a gain of $12.7 \%$, which still is an excess return of $43.1 \%$ compared to the best standard strategy. For 'Dyckerhoff', the corresponding excess return amounts to $64.6 \%$ in the absence of any costs and still $45.1 \%$ if $1 \%$ transaction costs must be paid.

\begin{tabular}{lccrc}
\hline company & strategy & $\begin{array}{c}\text { number of portfolio } \\
\text { changes }\end{array}$ & \multicolumn{2}{c}{ transaction costs } \\
\cline { 3 - 5 } WMF & 5\% strategy & 15 & $+31.0 \%$ & $\mathbf{1} \%$ \\
\hline 10\% strategy & 9 & $-0.7 \%$ & $-9.3 \%$ \\
& voting shares only & 0 & $-43.3 \%$ & $-43.3 \%$ \\
& non-voting shares only & 0 & $-30.4 \%$ & $-30.4 \%$ \\
\hline Dyckerhoff & 5\% strategy & 14 & $+48.8 \%$ & $+29.3 \%$ \\
& 10\% strategy & 6 & $+19.2 \%$ & $+12.2 \%$ \\
& voting shares only & 0 & $-15.8 \%$ & $-15.8 \%$ \\
& non-voting shares only & 0 & $-23.1 \%$ & $-23.1 \%$ \\
\hline
\end{tabular}

Table 4: Total returns of four trading strategies for 'WMF' and 'Dyckerhoff' in the presence of transaction costs.

5 The relevant missing values occur in the last week of 1989 (WMF) and the last week of 1991 (Dyckerhoff). Due to holidays, there were only two trading days in both weeks. 


\section{Conclusions and Further Notes}

Voting and non-voting shares of ten German companies have been analyzed for fractional cointegration, using weekly observations over time periods between 7 and 22 years. The Phillips-Perron t-test, which we applied to the cointegration regression residuals, provides strong evidence that seven pairs of these stocks are fractionally cointegrated. The long-memory parameter estimates for the equilibrium error process vary between 0.5 and 0.8 , which implies that the equilibrium errors are not stationary. Moreover, a potentially useful interpretation of the cointegration vector estimates in terms of relative risk and return has been introduced. Thereby, the riskier of the two cointegrated stocks can be identified easily.

For two pairs of voting and non-voting shares, the individual series are found to be trend stationary, so that the concept of cointegration is not applicable. Yet, trend stationarity contradicts the efficient market hypothesis, too. For only one pair of stocks, the hypothesis of no cointegration cannot be rejected at the $5 \%$ significance level (but at the $7.5 \%$ level).

In order to show that fractional cointegration of asset prices indeed violates the efficient market hypothesis, a simple trading strategy has been proposed and evaluated for two companies. For the evaluation, we used a second sample period that had not been used for estimation. In both cases, the strategy leads to considerable excess returns compared to permanent holding of only one kind of shares - even in the presence of realistic trading costs.

This result should not hide the fact that fractional cointegration of asset prices cannot be explained by trading costs in general. The reason is that it is possible to point out the more promising asset of the two at any time, so that rational and informed individuals will never buy the other one at the current price. The point is that someone who wants to buy e.g. 'Lufthansa' stocks for whatever reason will never buy voting shares if it is known that non-voting shares are more promising. So no extra trades are necessary in order to invoke the market forces that restore equilibrium.

A related argument in favour of the efficient market hypothesis relies on high information costs. Indeed, it is (at least initially) quite expensive to find out which asset is the more promising one, so that it might be rational not to "buy" this information. However, this argument can only explain very small deviations from efficiency, because information costs are constant whereas expected profits from excess returns increase in 
the number of shares held. So for major stockholders or fund managers, relative information costs are small.

A completely different argument, that might explain cointegrated asset prices in an efficient market, is that the two considered stocks merely look cointegrated and that this apparent cointegration is informationally efficient. The nature of this argument is best clarified by a naïve example: Consider two companies that solely differ in their probabilities of bankruptcy, which are public knowledge. The probability of bankruptcy of company $\mathrm{A}$ is constant while that of company $\mathrm{B}$ varies over time around a constant. If the stock market is informationally efficient, the two corresponding stock prices seem cointegrated as long as no bankruptcy occurs. So in a model with varying risks, apparent cointegration of stocks of two different companies can be informationally efficient. However, this argument cannot explain cointegrated prices of two stocks issued by the same company. If the company goes bankrupt, voting as well as non-voting shares are equally worthless.

A closely related argument, which directly refers to voting and non-voting shares, is based on the value of the voting right: Since a takeover premium is only paid for voting shares, the difference between voting and non-voting share prices - the so-called voting premium - should rise, if the probability of a takeover increases or if there is a rumour about an imminent takeover (cf. Rydqvist, 1996). Consequently, periodically arising rumours could cause apparent cointegration of voting and non-voting shares.

A more convincing argument for the German stock market, where serious takeover contests are very unlikely (see Franks \& Mayer, 1994, or Kojima, 1995), is given by Zwiebel (1995). Zwiebel argues that benefits of control are divisible among a coalition of shareholders, so that even holders of small blocks may extract a part of these benefits. Therefore, a voting premium may exist even if takeover contests are impossible. Here, the premium depends on the ownership distribution and the total benefits of control.

The nature of these corporate control arguments is static. They can explain why voting shares are more expensive than non-voting shares at a given time, but they cannot explain the dynamic phenomenon of cointegration. Certainly, one could reason that quantities like ownership distribution or probability of takeover, that determine the voting premium in these considerations, might fluctuate in a way that voting and nonvoting shares seem cointegrated. However, this consistently being the case (for seven companies over up to 22 years !) investors can expect this regularity to persist and may try to exploit it with a trading strategy like the one proposed in Section 5. If this is done by many investors, market forces drive the system into equilibrium, so that in the end the 
voting premium is roughly constant over time.

To sum up it can be said that the presented evidence for fractional cointegration of voting and non-voting shares seems to contradict the efficient market hypothesis even if transaction costs, changing risks and corporate control arguments are taken into account.

\section{References}

ANDREws, D. W. K. (1991): "Heteroskedasticity and autocorrelation consistent covariance matrix estimation", Econometrica, 59, 817-858.

Baillie, Richard T. (1996): "Long memory processes and fractional integration in econometrics", Journal of Econometrics, 73, 5-59.

Baillie, Richard T. and Tim Bollerslev (1994): "Cointegration, fractional cointegration and exchange rate dynamics", Journal of Finance, 49, 737-745.

Booth, G. Geoffrey and Yiuman Tse (1995): "Long memory in interest rate futures markets: A fractional cointegration analysis", The Journal of Futures Markets, 5, 573584.

Campbell, John Y., Andrew W. Lo and Y. Craig MacKinlay (1997): The Econometrics of Financial Markets, Princeton University Press.

Cerchi, Marlene and Arthur Havenner (1988): "Cointegration and stock prices. The random walk on wall street revisited", Journal of Economic Dynamics and Control, 12, 333-346.

Cheung, Yin-Wong and Kon S. Lai (1993): "A fractional cointegration analysis of purchasing power parity", Journal of Business \& Economic Statistics, 11, 103-112.

Cheung, Yin-Wong and Kon S. Lai (1997): "Bandwidth selection, prewhitening, and the power of the Phillips-Perron test", Econometric Theory, 13, 679-691.

DitTMAnn, InGolf (1997): "Fehlende Werte bei nichtparametrischer Zeitreihenanalyse im Frequenzbereich", discussion paper.

Dittmann, Ingolf (1998): "Residual-based tests for fractional cointegration: A Monte Carlo study", University of Dortmund SFB 475 Technical Report 9/1998.

Dueker, Michael and Richard Startz (1998): "Maximum likelihood estimation of fractional cointegration with an application to U.S. and Canadian bond rates", Review of Economics and Statistics, forthcoming.

FAma, Eugene F. (1970): "Efficient capital markets: A review of theory and empirical work", Journal of Finance, 25, 383-417.

Fama, Eugene F. (1991): "Efficient capital markets: II", Journal of Finance, 47, 15751617.

Franks, Julian And Colin Mayer. (1994): "Ownership and control", working paper, Oxford University.

Geweke, John and Susan Porter-Hudak (1983): "The estimation and application of long memory time series models", Journal of Time Series Analysis, 4, 221-238. 
Granger, C. W. J. (1986): "Developments in the study of cointegrated economic variables", Oxford Bulletin of Economics and Statistics, 48, 213-228.

Granger, C. W. J. (1987): "Equilibrium, causality and error-correction models", Economic Notes, 0, 5-21.

Granger, C. W. J. and Roselyne Joyeux (1980): "An introduction to long-memory time series models and fractional differencing", Journal of Time Series Analysis, 1, 15-29.

Hamilton, James D. (1994): Time series analysis, Princeton University Press.

Kasa, Kenneth (1992): "Common stochastic trends in international stock markets", Journal of Monetary Economics, 29, 95-124.

Kojima, Kenji (1995): "Corporate governance: An international comparison", working paper, Kobe University.

KRÄMER, WALter (1997): "Kointegration von Aktienkursen", discussion paper.

Kunz, Roger M. And James J. Angel (1996): "Factors affecting the value of the stock voting right: Evidence from the Swiss equity market", Financial Management, 25, 7-20.

Lease, Ronald C., John J. McConnell and Wayne H. Mikkelson (1983): "The market value of control in publicly-traded corporations", Journal of Financial Economics, 11, 439471 .

Malkiel, Burton G. (1989): "Efficient Market Hypothesis", in Eatwell, John, Murray Milgate and Peter Newman (eds): The New Palgrave Finance, W. W. Norton, New York.

Phillips, P. C. B. and S. Ouliaris (1990): "Asymptotic properties of residual based tests for cointegration", Econometrica, 58, 165-193.

RYDQVIST, KRISTIAN (1996): "Takeover bids and the relative prices of shares that differ in their voting rights", Journal of Banking \& Finance, 20, 1407-1425.

TAYOR, MARK P. And IAN Tonks (1989): "The internationalisation of stock markets and the abolition of U.K. exchange control", The Review of Economics and Statistics, 332336.

Zingales, Luigi (1994): "The value of the voting right: A study of the Milan stock exchange experience", The Review of Financial Studies, 7, 125-148.

Zwiebel, JEFFREy (1995): "Block investment and partial benefits of corporate control", Review of Economic Studies, 62, 161-185. 